\title{
Involvement of Cajal-Retzius Neurons in Spontaneous Correlated Activity of Embryonic and Postnatal Layer 1 from Wild-Type and Reeler Mice
}

\author{
Agustí Aguiló, ${ }^{1,2}$ Theodore H. Schwartz, ${ }^{1}$ Vikram S. Kumar, ${ }^{1}$ Zita A. Peterlin, ${ }^{1}$ Areti Tsiola, ${ }^{1}$ Eduardo Soriano, ${ }^{2}$ \\ and Rafael Yuste ${ }^{1}$ \\ ${ }^{1}$ Department of Biological Sciences, Columbia University, New York, New York 10027, and 2Department of Animal and \\ Plant Cell Biology, Faculty of Biology, University of Barcelona, Barcelona 08028, Spain
}

Cajal-Retzius (CR) cells are a transient population of neurons in developing cortical layer 1 that secrete reelin, a protein necessary for cortical lamination. Combining calcium imaging of cortical hemispheres and cross-correlation analysis, we previously found spontaneous correlated activity among non-CR neurons in postnatal rat layer 1 . This correlated activity was blocked by GABAergic and glutamatergic antagonists, and we postulated that it was controlled by CR cells. We now investigate the correlated activity of embryonic and postnatal layer 1 in wild-type and reeler mice, mutant in the production of reelin. We find that mouse layer 1 also sustains patterned spontaneous activity and that CR cells participate in correlated networks.

After completing their radial migration (Rakic, 1974), developing pyramidal neurons make synaptic connections in the marginal zone (Marín-Padilla and Marín-Padilla, 1982), a relatively cellsparse region populated by Cajal-Retzius (CR) cells (Ramón y Cajal, 1904). As the cortex develops, the marginal zone becomes layer 1 and CR cells disappear, by either apoptosis or differentiation into nonpyramidal cells (Marín-Padilla, 1972; Parnavelas and Edmunds, 1983; Derer and Derer, 1990; Del Río et al., 1995). CR cells and their equivalents in hippocampus produce an extracellular matrix protein called reelin, defective or absent in mouse reeler mutants (D'Arcangelo et al., 1995; Hirotsune et al., 1995; Ogawa et al., 1995), which shows altered neuronal migration in neocortex, hippocampus, and cerebellum (Caviness and Sidman, 1973). Reelin is also involved in the axonal growth and synaptogenesis of entorhinal projections to the hippocampus (Del Río et al., 1995; Borrell et al., 1999). These findings indicate that layer 1 is likely to play a major role in cortical development.

Besides CR (horizontal) neurons, two other cell types are found in developing layer 1: vertical cells with descending axons and neurogliaform cells (Ramón y Cajal, 1904; Marín-Padilla, 1984; Hestrin and Armstrong, 1996; Zhou and Hablitz, 1996).

\footnotetext{
Received July 27, 1999; revised Sept. 3, 1999; accepted Oct. 4, 1999.

R.Y. is supported by the EJLB Foundation, the Arnold and Mabel Beckman Foundation, and National Eye Institute Grant EY 111787. E.S. is supported by CICYT Grant SAF-98/106/SAF97-1429-E, The Marató de TV3 Foundation, and the Ramón Areces Foundation. A.A. holds a Formación Personal Investigador (Ministerio de Educacion y Ciencia, Spain) fellowship. R.Y. and E.S. are supported by the Human Frontier Science Program. We thank Carla Shatz for advice, members of both laboratories for comments and help, and Ferran Burgaya for help genotyping mice.

Correspondence should be addressed to Rafael Yuste, Department of Biological Sciences, Columbia University, 1212 Amsterdam Avenue, Box 2435, New York, NY 10027. E-mail: rafa@cubsps.bio.columbia.edu.

Copyright (C) 1999 Society for Neuroscience $\quad 0270-6474 / 99 / 1910856-13 \$ 05.00 / 0$
}

These networks are present in embryonic marginal zone and are blocked by GABAergic and glutamatergic antagonists. Surprisingly, network activity in reeler mice displays similar characteristics and pharmacological profile as in wild-type mice, although small differences are detected. Our results demonstrate that the embryonic marginal zone has correlated spontaneous activity that could serve as the scaffold for the development of intracortical connections. Our data also suggest that reelin does not have a major impact in the development of specific synaptic circuits in layer 1.

Key words: reelin; marginal; neocortex; fura-2; imaging; networks

These non-Cajal-Retzius (NCR) cells also receive synaptic inputs (Hestrin and Armstrong, 1996; Zhou and Hablitz, 1996) and are GABAergic (Gabbott and Somogyi, 1986), whereas CR cells react with antibodies against glutamate, cholinesterase, calretinin, calbindin D-28K, and parvalbumin (Del Río et al., 1995; Huntley and Jones, 1990; Meyer et al. 1998).

Because of the resilience of orientation maps in visual cortex to manipulations of cortical inputs during development, it has been proposed recently that the activity of the marginal zone could generate a "protomap" of clustered horizontal connections (Galuske and Singer, 1996; Schmidt et al., 1999). This idea and the key role that spontaneous correlated activity has in CNS development (Shatz, 1990; Katz and Shatz, 1996) make it important to establish whether the marginal zone, which with the subplate are the earliest generated cortical layers, has spontaneous correlated activity.

In a previous study of postnatal marginal zone in hemisphere preparations, we discovered that NCR neurons had correlated increases in their intracellular free calcium concentration $\left(\left[\mathrm{Ca}^{2+}\right]_{\mathrm{i}}\right)$, indicative of coordinated spontaneous activity (Schwartz et al., 1998). These NCR networks were sensitive to synaptic blockers, and we postulated that they were controlled by $\mathrm{CR}$ neurons. To further investigate these networks and inquire whether the embryonic marginal zone also has correlated spontaneous activity, we have now performed similar experiments in isolated hemispheres from embryonic and postnatal wild-type (wt) and reeler mice. We find that, in mice, this correlated activity is already present in embryonic marginal zone and that CR neurons form part of these networks. Surprisingly, we do not find any major differences in correlated networks between wildtype and reeler mice, indicating that the layer 1 circuit is basically functional in reeler mice. 


\section{MATERIALS AND METHODS}

Strains and establishment of reeler phenotype. Animal handling and experimentation was performed in accordance with the National Institutes of Health Guide for the Care and Use of Laboratory Animals (National Institutes of Health publication number 86-23, revised 1987). We used $\mathrm{Balb} / \mathrm{C}$ wild-type mice ranging from embryonic day 17 (E17) to postnatal day 10 (P10). C7 mice were also used for wild-type E15 experiments. Reeler mice of the Orleans (rl-Orl) strain were used from E15 to P6 and had a Balb/C genetic background. The reeler phenotype was identified in postnatal mice using parasagittal slices of the cerebellum to detect abnormal gyri and lamination and transverse slices of hippocampus to detect whether the pyramidal CA1 layer was intact. In embryonic animals and in some postnatal animals, we used PCR to detect the transposable element in tail extracts. Genomic DNA was used in a PCR reaction with primers to amplify the wild-type reelin gene (CGACTGCTCTGTCTTCAGTCACGAG) sequence only expressed in wt reeler gene, the (CTCGAGTGAGGTCCAGTGGCTT) sequence expressed both in wt and mutated reelin gene, and the transposable element (GGATGGACCTGGAGAGCATCATCC) as marker of the mutant gene.

Animal dissection. Mice were anesthetized by hypothermia, and their brains were removed and placed in oxygenated artificial CSF (ACSF) (in mM: $\mathrm{NaCl} 120, \mathrm{KCl} 3$, D-glucose 10, $\mathrm{NaHCO}_{3} 26, \mathrm{NaH}_{2} \mathrm{PO}_{4} 2.25, \mathrm{CaCl}_{2}$ 2, and $\mathrm{MgSO}_{4}$ 2, $\mathrm{pH} 7.4$, oxygenated with $95 \% \mathrm{O}_{2}-5 \% \mathrm{CO}_{2}$ ). For embryonic experiments, pregnant mice were anesthetized with ketaminexylazine, and pups were surgically removed and placed in ice-cold ACSF. Brains were dissected by splitting the hemispheres with a razor blade and gluing them to the bottom of a Petri dish filled with ACSF. The pia was carefully removed under a dissecting microscope.

Loading of fura-2 and pharmacology. Fura-2 AM (Molecular Probes, Eugene, OR) was dissolved in DMSO with $0.001 \%$ Pluronic acid (Molecular Probes). Following Schwartz et al. (1998), we used a two-step incubation protocol. First, we incubated the hemisphere with $2-5 \mu \mathrm{l}$ of the $5 \mathrm{~mm}$ fura-2 AM for 1-2 min. Then, we performed a second incubation with 3-5 ml of oxygenated ACSF with 5-10 $\mu \mathrm{M}$ fura-2 AM. The second incubation took at least $20 \mathrm{~min}$ and was performed in the dark at room temperature $\left(\sim 25 \mathrm{C}^{\circ}\right)$. AP-5 $(50 \mu \mathrm{M})$, CNQX $(20 \mu \mathrm{M})$, bicuculline $(30 \mu \mathrm{M})$, and TTX $(1 \mu \mathrm{M})$ were dissolved in ACSF and bath applied. All drugs were obtained from Sigma (St. Louis, MO).

Imaging. After dye incubation, the hemisphere was placed under a fluorescent microscope (BX50WI; Olympus Opticals, Tokyo, Japan) equipped with 380 and $340 \mathrm{~nm}$ excitation filters and differential interface contrast (DIC) optics. For imaging, we used a silicon-intensified tube camera (Hamamatsu C2400-08) and a frame grabber (LG-3; Scion Corp., Frederick, MD), connected to a Macintosh computer (Apple Computers, Cupertino, CA). Fluorescent images were taken at $380 \mathrm{~nm}$ excitation using time-lapse imaging ( 15 averaged frames, every $4 \mathrm{sec}$ ) for periods of up to $40 \mathrm{~min}$. Images were acquired and processed by $\mathrm{NIH}$ Image. To prevent photobleaching, we used a shutter controlled by custom-written macros. The sample was perfused with standard $(3 \mathrm{~mm}$ $\mathrm{KCl}$ ) or high-potassium ACSF (in mM: $\mathrm{NaCl} 77, \mathrm{KCl}$ 50, D-glucose 10, $\mathrm{NaHCO}_{3} 26, \mathrm{NaH}_{2} \mathrm{PO}_{4} 2.25, \mathrm{CaCl}_{2} 2$, and $\mathrm{MgSO}_{4} 2$ ). Spontaneous activity was imaged using 20,40 , and $60 \times$ objectives.

Single cell reconstruction. Neurons were filled with a patch pipette containing $1 \%$ biocytin injected with depolarizing current pulses $(0.3 \mathrm{nA}, 10$ $\mathrm{Hz}$ ) for $30 \mathrm{~min}$. After fixation in $4 \%$ paraformaldehyde, slices were rinsed three times in PBS and incubated in $10 \%$ methanol- $3 \% \mathrm{H}_{2} \mathrm{O}_{2}$ for $30 \mathrm{~min}$. Slices were rinsed in PBS and incubated in a horseradish peroxidase-conjugated avidin-biotin complex (Peroxidase Elite ABC Kit; Vector Laboratories, Burlingame, CA) prepared in $0.75 \%$ Triton $\mathrm{X}-100$ for $3 \mathrm{hr}$ at room temperature. Slices were then rinsed and reacted with a $2.5 \mathrm{mg} / \mathrm{ml}$ diaminobenzidine (DAB) solution in Tris buffer for 20 min. Biocytin-injected neurons were revealed by the DAB precipitate. Before final dehydration through an ethanol series, slices were stained with Nuclear yellow for demarcation of cortical layers.

Analysis. Changes in fluorescence in multiple cells were analyzed with a program written in interactive data language (Research Systems, Inc., Boulder, $\mathrm{CO})$. We defined the fluorescence change over time as $\Delta F / F=$ $\left(F_{0}-F_{1}\right) / F_{0}$. The onset of each calcium transient for every cell was determined using an algorithm that defined the onset as the frame after which the $\Delta F / F$ change was larger than a given set threshold, typically a 3-5 pixel value units change per frame. This threshold algorithm was very sensitive but produced false positives in some cells in which noisy baseline values were scored as transients, as determined by visual inspection. Calcium transients detected by the program were carefully inspected, and spurious events were removed before displaying the onset times on a raster plot. These raster plots were used to calculate the matrix of asymmetric correlation coefficients between all cell pairs, i.e., the proportion of times that a cell becomes active when another cell is also active. We then used contingency tables and $\chi^{2}$ tests to detect which correlation coefficients were significantly greater than expected. Significant correlation coefficients were then used to generate a correlation map in which lines link neurons whose asymmetric correlation coefficient are significant $(p<0.05)$ and in which the thickness of a line connecting any two cells represents the magnitude of the greater asymmetric correlation coefficient between the cells.

To test whether transients showed associations between neurons, we measured the number of simultaneous activations in a recording and used it as a test statistic. To determine its $p$ value, we computed the distribution of the statistic under the null hypothesis of independent transients. To do this, we used Monte Carlo simulations with 1000 replications. The $p$ value was then calculated as the proportion of the 1000 replications in which the test statistic exceeded the test statistic computed from real data. To simulate independent realizations of the transients, the number of transients in each train was preserved, but the times of the transients were chosen randomly. This approach is equivalent to assuming that the distributions of the transients behave as Poisson processes with varying underlying rates. We tested this assumption with control computation of $p$ values using randomized starting times for each train and wrapping around the ends, without finding any different results.

We also performed two additional tests on each data set. The first detected cells that activated simultaneously and treated the number of coactive groups over the entire recording as the test statistic. The second test detected groups of cells that activated simultaneously more than once and used that number as the test statistic. Monte Carlo simulations were again used to estimate the significance of these two test statistics. Nonparametric tests were used to compare measurements. Comparison among $p$ values was not attempted because of differences in sizes from the original populations.

\section{RESULTS \\ Fura-2 AM loads CR and NCR neurons in developing mouse layer 1}

To characterize the spontaneous activity pattern present in developing layer 1 in wild-type mice, we imaged hemispheres from 51 embryonic and postnatal animals (E15 to P10). Isolated hemisphere preparations, when maintained under adequate oxygenated solution, can be used for several hours for physiological studies of developing layer 1 (Schwartz et al., 1998). After removal of the pia, layer 1 is the most superficial cell layer and can be clearly distinguished because of the distinct horizontal dendritic profiles of CR neurons (Fig. 1). To assess morphologically which types of neurons were loaded with fura-2, we used DIC from layer 1 slices to identify whether labeled neurons were CR or NCR (Fig. 1A). To identify CR neurons, we applied the criteria that $\mathrm{CR}$ cells under DIC have one main dendritic process, oriented parallel to the pial in apparently random directions (Schwartz et al., 1998). We confirmed this criteria for the mouse layer 1 using whole-cell recording of neurons that had a horizontal process under DIC to fill them with Lucifer yellow or biocytin. Camera lucida reconstructions of biocytin filled neurons demonstrated their clear CR morphologies and processes (Fig. 1C). In layer 1 slices, we found that CR and NCR neurons labeled equally with fura-2 AM and, in hemispheres, we clearly detected in the fluorescent cells with horizontal processes, indicative of CR neurons, as well as other neurons without clearly visible processes, presumably NCR cells. In addition CR cells were usually larger than NCR cells. We concluded that fura-2 AM incubations loaded both types of layer 1 neurons in both slices and hemisphere preparations from developing mice. 
A

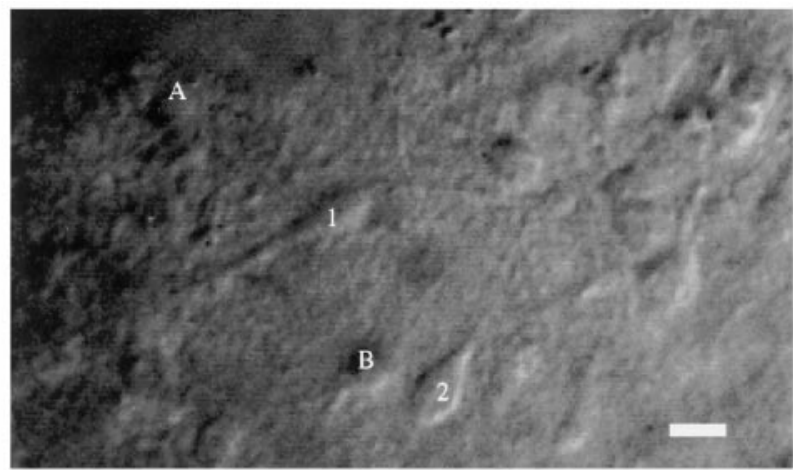

B

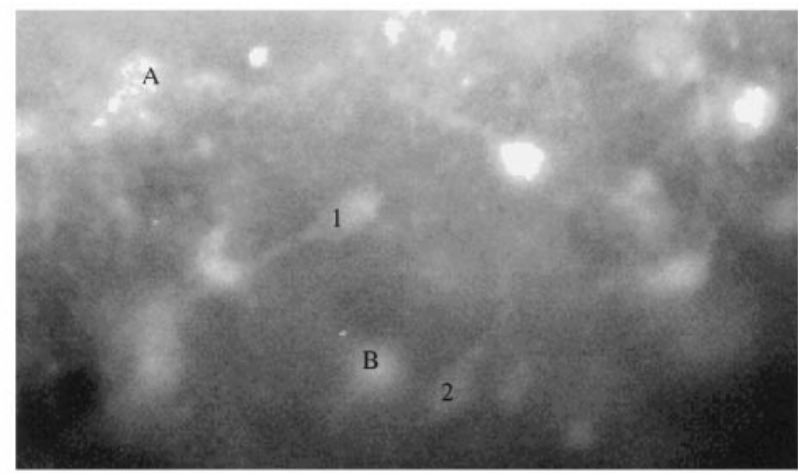

C

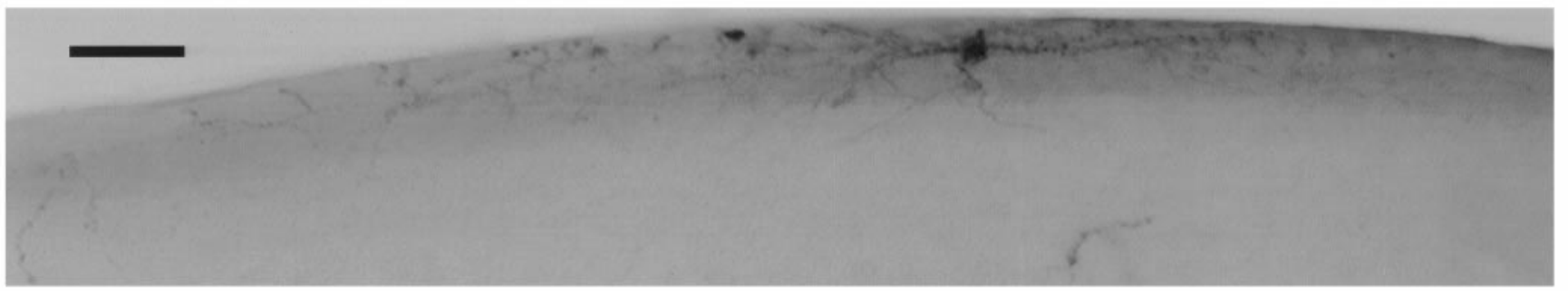

D

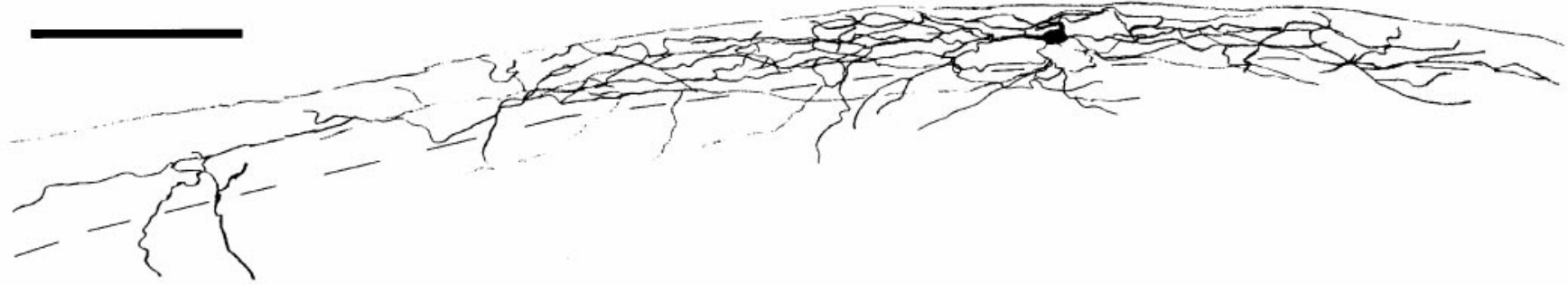

Figure 1. Fura-2 loading of CR and non-CR neurons in mouse layer 1. A, DIC image of a tangential brain slice from a P1 mouse cortex. The slice is viewed from its pial surface after the pia has been removed. Several CR neurons (numbers) can be distinguished by their long dendritic process. Putative non-CR cells (letters) lack any major process. Scale bar, $20 \mu \mathrm{m}$. B. Fluorescence image of the same region after staining with fura-2 AM. Note how both CR and putative NCR neurons are labeled by the indicator. $C$, Photomicrograph of a processed coronal slice containing a biocytin-filled CR cell. The major horizontal process can be distinguished. Scale bar, $50 \mu \mathrm{m}$. $D$, Camera lucida reconstruction of neuron shown in $C$. The layer 1 border is drawn with a stippled line. Scale bar, $100 \mu \mathrm{m}$.

\section{Networks of spontaneously coactive neurons in wild- type mouse layer 1}

In hemisphere preparations, spontaneous increases in $\left[\mathrm{Ca}^{2+}\right]_{\mathrm{i}}$ were detected in dozens of neurons (Fig. 2). Both CR and NCR neurons participated in this spontaneous activity (Fig. $2 C$ ). These spontaneous calcium transients were slow, with rise times of 4-20 sec and decay times of 20-50 sec. These time courses enabled us to follow their occurrence using time lapse imaging with slow frame rates ( $1 \mathrm{frame} / 4 \mathrm{sec}$ ) for long periods of time (up to $40 \mathrm{~min}$ ) (Fig. 2C).

To analyze the optical recordings, we first transformed the fluorescence intensities over time for each neuron into a raster plot in which the time of initiation of each calcium transient for each cell was marked (Fig. 2D). Although from visual inspection of the recordings it was not possible to detect clear spatiotemporal patterns to the activation, in many experiments our analysis showed spontaneous correlated activation of many neurons (Fig. $2 D$, cells $8-10)$. To quantify the degree of correlation present in the data set, we counted the number of times that any two cells had simultaneous onset activation times (i.e., in the same frame) and compared that number with the number of simultaneous activation times present in a distribution of 1000 random experiments, created with Monte Carlo simulations (Fig. 3A; see Materials and Methods). This comparison gave us a $p$ value for the real data set that described the probability that the number of coactivations present in it was caused by chance and thus characterized the overall level of coactivation present in the recordings. This $p$ value changed from preparation to preparation but was typically similar in recordings taken from the same preparation. It should be noted that this $p$ value was normalized for the number of neurons, activation rates, and time resolution of the recording, because the Monte Carlo simulations were created using the same number of neurons, activations, and time intervals present in the real data set (see Materials and Methods). This statistical analysis is only applicable if there are enough activations in a recording; otherwise, the test statistic (number of coactivations) cannot be computed. Using this analysis, we found that a substantial number of experiments (four of five record- 

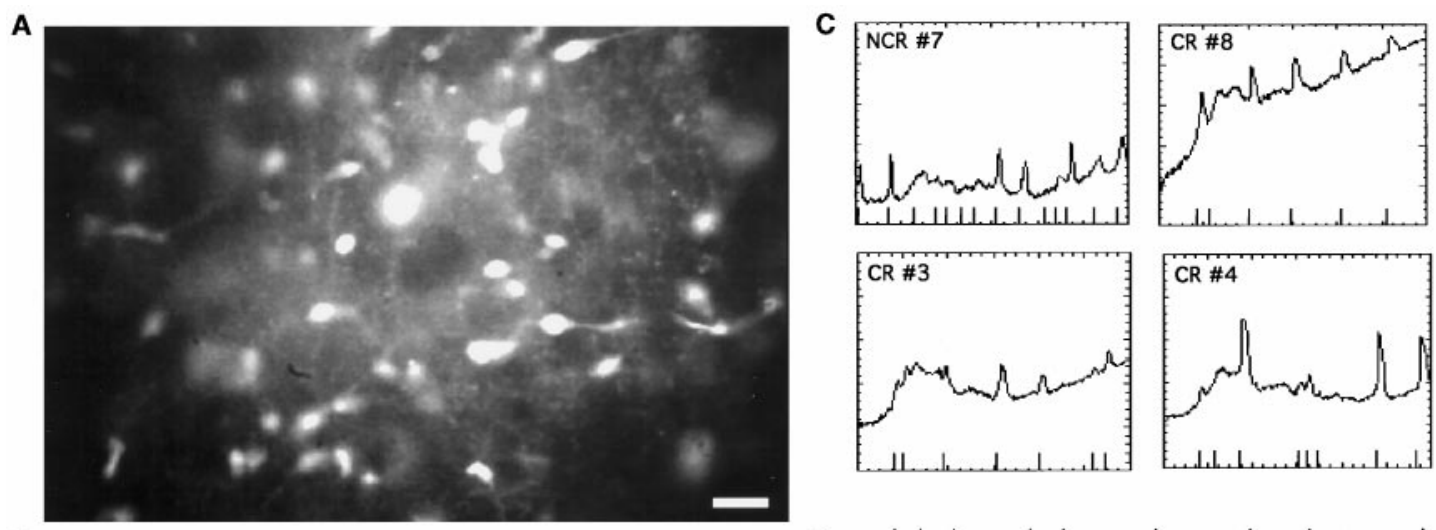

B
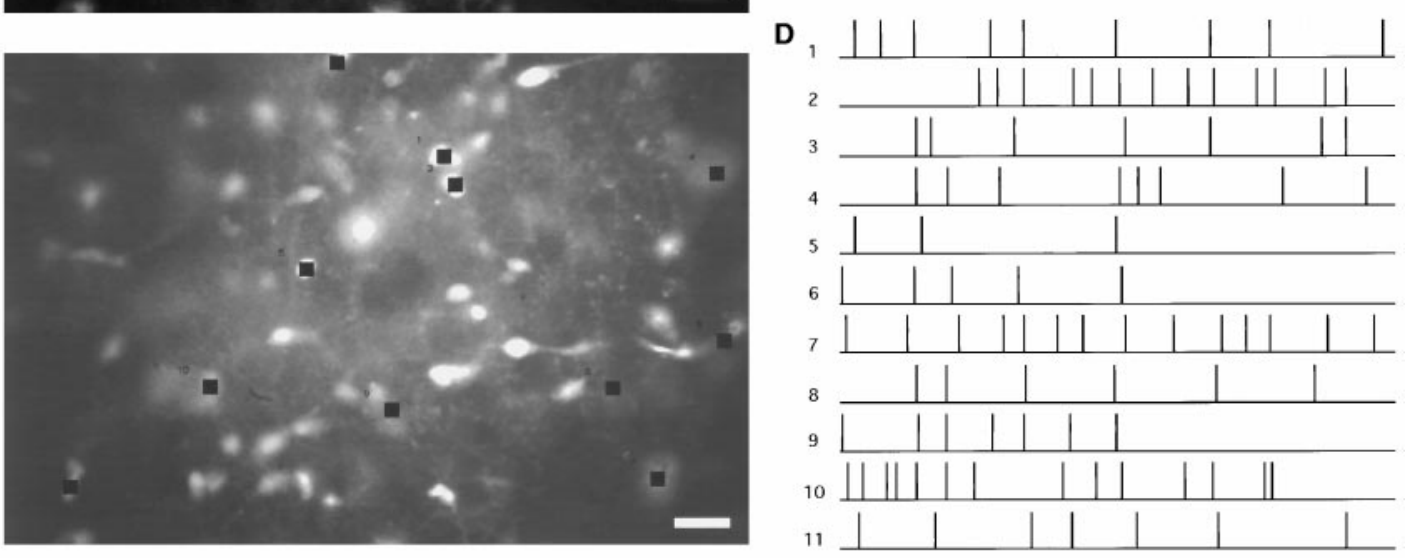

Figure 2. Spontaneous calcium transients in wild-type layer 1 show complex spatiotemporal patterns. $A$, Fluorescence image of a cortical hemisphere from a P3 mouse loaded with fura-2 AM. Many labeled neurons are visible. Scale bar, $20 \mu \mathrm{m}$. B, Cells chosen for the analysis. Black squares indicate cells exhibiting transients. Neurons 3,4 , and 8 were identified as Cajal-Retzius. $C$, Plots of $-\Delta F / F$ over time measured in four representative cells during spontaneous activity. Each fluorescence transient is marked with a time stamp (lines) seen at bottom of graph (see Materials and Methods). Note that the program successfully detects all calcium transients. Time axis, $\% 1200 \mathrm{sec} ;-\Delta F / F$ axis, $-5 / 20$ (percent). $D$, Composite raster plot of all cells chosen in $B$ indicating the onset of each calcium transient as displayed in $C$. Each line represents a cell, and each tick mark represents the time of onset of a calcium transient. Note that the spontaneous activity does not follow any clear pattern, although correlated activation of two or more cells can be detected. Duration, $600 \mathrm{sec}$.

ings in standard ACSF and 30 of 51 recordings in high $\mathrm{K}^{+}$ ACSF; see below) had significant levels of coactivation $(p<$ $0.05)$. These results show that, like rat developing layer 1 (Schwartz et al., 1998), mouse layer 1 can sustain spontaneous correlated activity.

\section{CR neurons participate in correlated networks in mouse layer 1}

To identify the neurons responsible for the correlated activity, we first plotted the significant asymmetric correlation coefficients, as assayed with $\chi^{2}$ contingency tables, among all neuron pairs (Fig. $3 B$; Materials and Methods). This analysis produced maps with many significant correlations among neurons. Nevertheless, given the large number of active neurons present in our recordings, we reasoned that some of these putative correlations could be caused by chance coactivations. To further inquire which correlation was likely to be real, we used additional analysis, aimed at identifying (1) multiple coactivations of two neurons (two cells, many times) or (2) coactivation of multiple neurons (many cells, once) (Fig. $3 C$ ). Both classes of events are very unlikely to occur because of chance given the multiplicative effect of low probabilities. Indeed, further Monte Carlo simulations of these groups in most cases produced $p$ values for the occurrence of multiple coactivations of either type equal to zero, i.e., multiple coactivation never occurred in the simulated randomized experiments. This analysis showed that groups of neurons, ranging from two to nine neurons per group, sustained simultaneous calcium transients, therefore forming networks of coactive neurons. Using these two types of multiple coactivation, we then created correlation maps in which lines linked neurons that participated in multiple coactivation events (Fig. 3D). These maps invariably showed that different networks of coactive neurons overlapped in the same territories, and, in many cases, individual neurons participated in more than one network. We concluded that overlapping networks of coactive neurons exist in mouse developing layer 1.

In our previous study of the spontaneous activity of rat developing layer 1, we did not detect instances of CR neurons participating in the coactive networks. Given the low activation rate that CR neurons had in our recordings from rat preparations, we reasoned that this negative result could have been produced because low activation rates made it unlikely that we record their coactivations with other neurons (Schwartz et al., 1998). In our data from rat layer 1 , however, we noticed that glutamate receptor antagonists blocked the coactivation of the networks. Given the fact that CR neurons are glutamatergic (Del Río et al., 1995), we proposed that they could control the coactivation of NCR cells.

In our recordings from mouse layer 1 , we indeed found that $\mathrm{CR}$ neurons were part of the correlated networks (cell 4 in Figs. 2, $3 D$ ). Analysis of the correlation maps produced with both multiple coactivation detection methods explained above showed that 
A

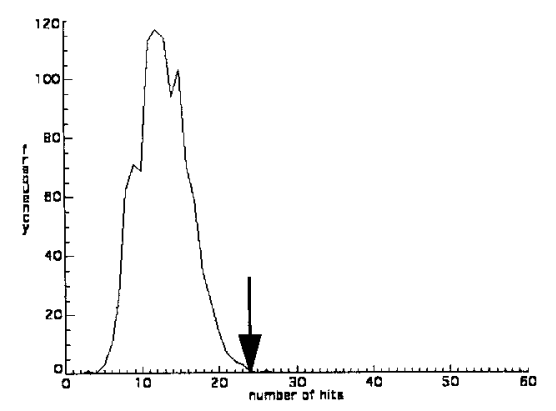

B

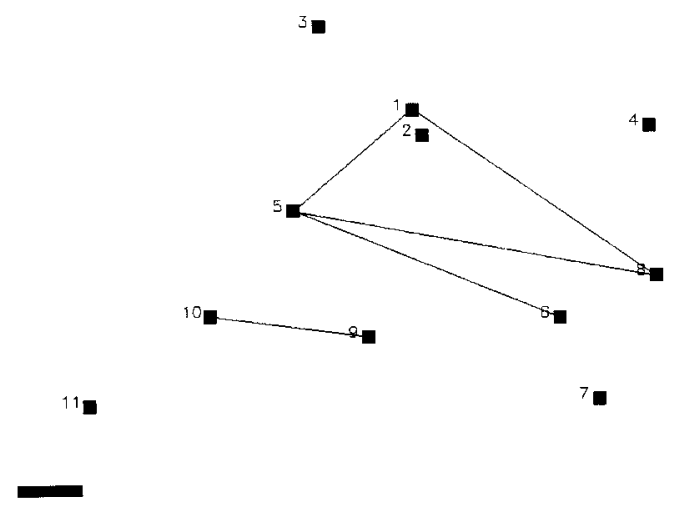

C

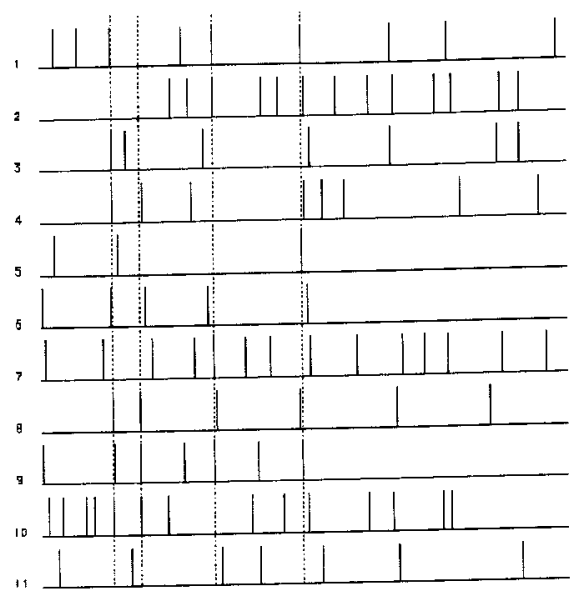

D

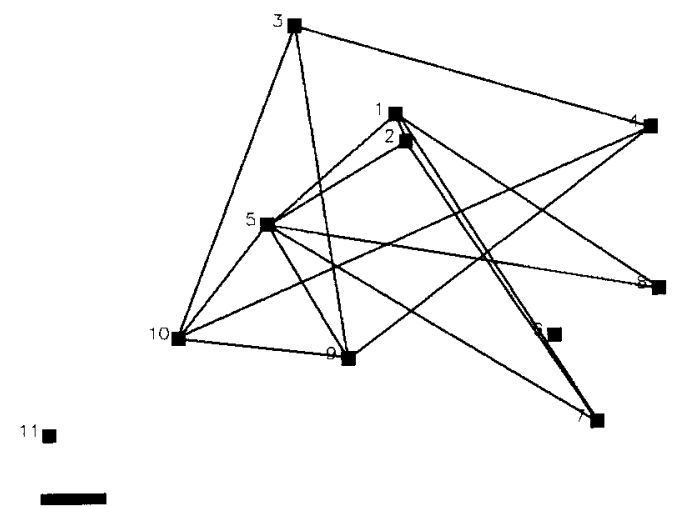

Figure 3. Networks of CR and NCR cells in wild-type layer 1. A, Distribution of pairwise correlations ("hits") found in the real (arrow) and simulated (line) data set from Figure 2. The number of correlated events in the real data set is greater than those obtained in 1000 Monte Carlo simulations (bell-shaped curve; see Materials and Methods). B. Correlation map of cells imaged in Figure 2. Each black square represents an active cell. Lines link cells with a statistically significant correlation coefficients (see Materials and Methods). $C$, Raster plot of the experiment showing which neurons fire simultaneously in groups (dotted lines). $D$, Correlation map based on the groups of cells firing simultaneously in $C$. Note how the coactive groups cover the same cortical territory. Note also how CR cells 3,4 , and 8 are correlated with both CR and NCR cells. Scale bar, $10 \mu \mathrm{m}$.

CR neurons were involved in coactive networks with NCR and other CR cells (24 of $37 \mathrm{CR}$ cells from 18 of 51 movies).

\section{Development of correlated networks in wild-type layer 1}

To study whether there were developmental changes in these correlated networks, we imaged the spontaneous coactivations of layer 1 hemispheres at different ages, ranging from E15 to P10 (Figs. 4, 5). To characterize the overall level of correlations, we used the $p$ value of the simultaneous correlations, calculated as explained. Neither the proportion of experiments that showed significant $p$ values $(p<0.05)$ nor the average $p$ value that resulted from pooling all the experiments together changed significantly in the ages examined (Fig. 6A). These results show, for the first time, that correlated spontaneous activity is present in the marginal zone at embryonic ages, and they also indicate that the overall level of spontaneous correlations is relatively constant in the late embryonic and early postnatal layer 1 in wild-type mice. Similarly, there did not appear to be a significant developmental trend in the average rate of spontaneous activation (Fig. $6 B$ ) or the average number of cells that were spontaneously active (Fig. $6 C$ ). Finally, we found involvement of CR neurons in the networks at different ages, without any clear developmental trend (Fig. 6D). We conclude that these features of the layer 1 networks are preserved without major changes during embryonic and early postnatal development.

\section{Coactive networks in wild-type mouse layer 1 are mediated by glutamate and GABA}

To characterize whether these correlated networks were mediated synaptically, we used bath applications of antagonists of glutamate receptors, GABA-A receptor, and sodium channel and measured their effect on the control $p$ values, calculated from recordings of the same neurons under identical experimental conditions (Fig. $6 E$ ). The $p$ value was again computed with a Monte Carlo simulation that generated 1000 random iteration of the data (see Materials and Methods) to produce a random distribution of the number of coincident calcium transients. The 

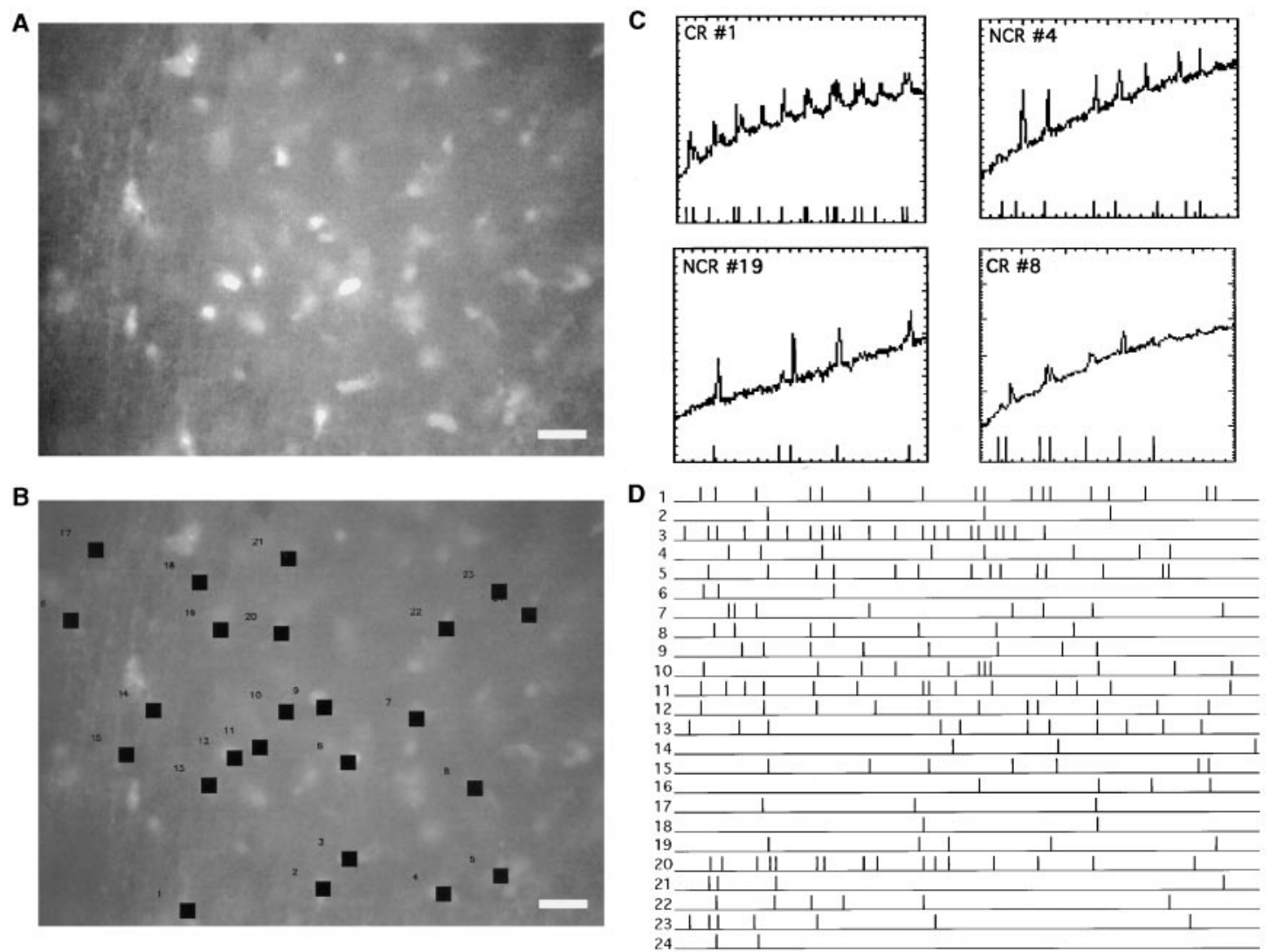

Figure 4. Imaging spontaneous activity in embryonic layer 1. $A$, Fluorescence image of a cortical hemisphere from an E18 mouse loaded with fura-2 AM. Many labeled neurons are visible. Scale bar, $20 \mu \mathrm{m} . B$, Cells analyzed. Neurons $1,2,3,6$, and 8 were identified as Cajal-Retzius. $C$, Plots of $-\Delta F / F$ over time measured in four representative cells during spontaneous activity. Again, the onset of each fluorescence transient is marked with a time stamp seen at the bottom of graph (see Materials and Methods). Time axis, $\% 1200 \mathrm{sec} ;-\Delta F / F$ axis, $-5 / 20$ (percent) for cells 1,4 , and $19 ;-10 / 50$ (percent) for cell 8. $D$, Composite raster plot of all cells chosen in $B$. Duration, 600 sec.

$p$ value for the real movie was then calculated directly by comparing its number of coincident events with this distribution. To ensure that the level of activation of the neurons was high and thus enhance our detection of possible effects of these blockers on the correlations, we used high-potassium (50 mM) ACSF instead of normal (3 mM) ACSF, because, from our previous work in rat layer 1 and from control experiments in mouse layer 1 , both 3 or $50 \mathrm{~mm} \mathrm{KCl}$ produced significant $p$ values in most of the recordings (for $3 \mathrm{~mm}$, four of five recordings with $p<0.05$; mean $p=0.058$; for $50 \mathrm{~mm}, 27$ of 48 recordings with $p<0.05$; mean $p=0.162$ ).

In mouse layer 1 , the sodium channel blocker TTX, which blocks axonal conduction, produced increases in the average $p$ value from control recordings, indicating that their application reduced the correlations present (Fig. 6E). These increases in $p$ value occurred in the absence of significant effects in the activation rate or in the number of active neurons, suggesting that the spontaneous calcium transients still occur but become decorrelated in TTX. Similar results were found with the glutamate receptor antagonist $\mathrm{CNQX}$ and with the GABA-A antagonist bicuculline methiiodide (BMI) (Fig. 6E). Results from experiments with the NMDA receptor antagonist AP-5 also produced a decorrelation of the spontaneous activity. Again, their effects occurred in the absence of effects on activation rates or number of active cells. Because CR neurons are glutamatergic and NCR neurons are GABAergic, these results are consistent with the network correlations being mediated synaptically by NCR and CR neurons.

\section{Networks of spontaneously coactive neurons in reeler mouse layer 1}

We wondered whether these coactive networks were affected in reeler mice. Because of disrupted reelin production by CR cells, these mice have profound defects in cortical lamination and in afferent pathfinding in hippocampal marginal zone (Caviness and Sidman, 1973; D’Arcangelo et al., 1995; Hirotsune et al., 1995; Ogawa et al., 1995; Del Río et al., 1997; Borrell et al. 1999). Therefore, we expected that the connectivity in layer 1 would also be disrupted because of both migratory or pathfinding defects.

To explore layer 1 networks in reeler, we used animals from the Orleans reeler strain ( $\mathrm{rlOrl}$ ), a frame-shift mutation resulting from the insertion of a P1 transposable element within the coding sequence of reelin gene (Takahara et al., 1996; De Bergeyck et al., 1997). In hemispheres from reeler mice, we also encountered spontaneous calcium transients in both CR and NCR neurons with a complicated spatiotemporal pattern (Fig. 7). Statistical analysis of these data sets computing a global $p$ value for the entire correlation matrix (as above) also produced significant levels of correlated activity in most recordings (in standard ACSF, two of three recordings with $p<0.05$; mean $p=0.18$; in high K ACSF, 16 of 33 recordings with $p<0.05$; mean $p=0.151$ ). Further analysis focusing on the occurrence of either multiple correlations of the same two neurons of single correlations of multiple neurons also indicated that the correlated activity was extremely unlikely to be attributable to chance (Fig. 8). This 
A

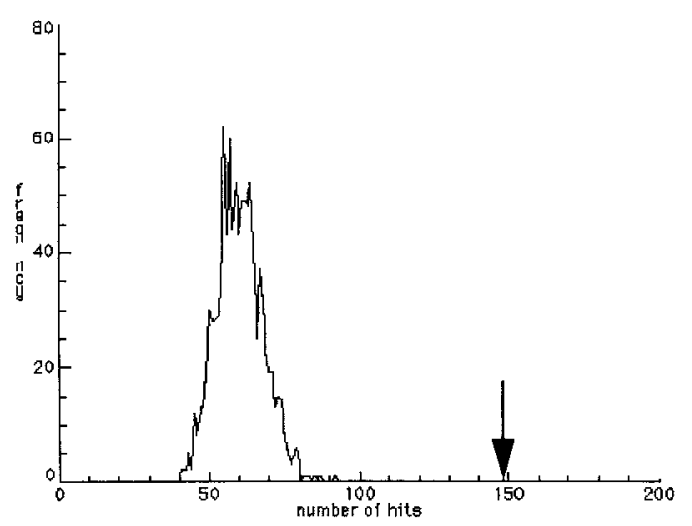

B

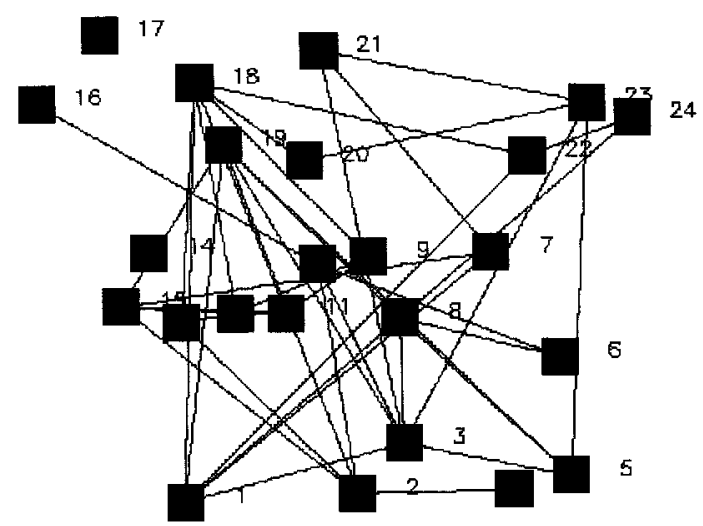

C

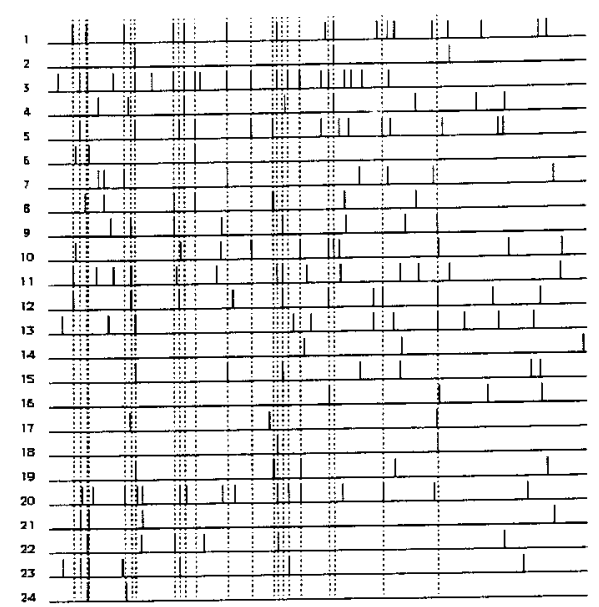

D

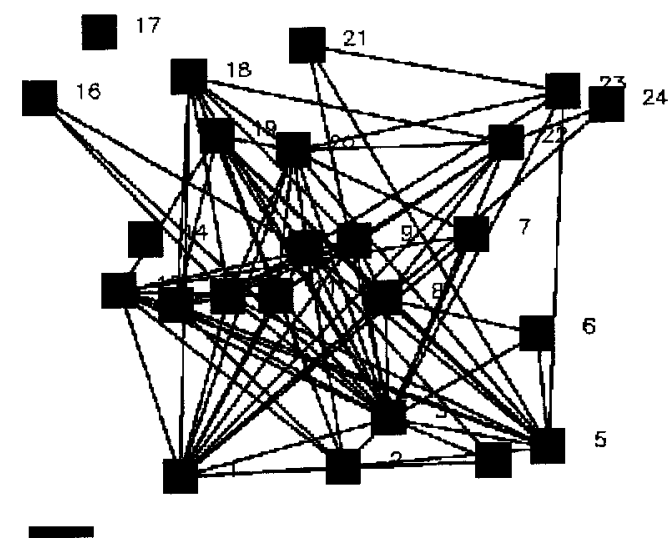

Figure 5. Networks of CR and NCR cells in embryonic layer 1. A, Distribution of pairwise correlations found in the real (arrow) and simulated data set from Figure 4. B, Correlation map of cells imaged in Figure 4. C, Raster plot of the experiment highlighting groups of coactive neurons (lines). D, Correlation map based on the groups of cells firing simultaneously in $C$. Note how CR cells $1,2,3,6$, and 8 are correlated with both CR and NCR cells. Scale bar, $10 \mu \mathrm{m}$.

analysis also showed the presence of networks of correlated neurons superimposed in the same cortical territories (Fig. 8D). These networks were composed of both NCR and CR (cell 12 in Figs. 7, 8) neurons. Thus, we concluded that the reeler phenotype did not disrupt the appearance of the correlated networks in developing layer 1 and that CR neurons are also part of these networks.

\section{Quantitative differences in correlated activity in reeler hemispheres}

Although the networks found in reeler hemispheres resembled those found in wild-type mice, we wondered whether there could be significant differences in them when compared during their development. We therefore performed a developmental study of the networks in reeler mice (Fig. 9) using the same ages that we had used previously for our wild-type study (Fig. 6). In this comparison, we noticed a developmental trend in reeler hemispheres to be more decorrelated with age, as revealed by both a decrease in the number of hemispheres with significant correlations $(p<0.05)$ and an increase the average $p$ value for the correlation present in all the experiments (Fig. 9A). Compared with wild type, reeler hemispheres had lower rates of activation (Fig. 9B) and increased number of active cells, a small effect that was statistically significant at $\mathrm{P} 1$ and $\mathrm{P} 4$ (Fig. 9C, asterisks). Finally, the participation of CR neurons in the networks of both reeler and wild-type hemispheres was similar (Fig. 9D). These results suggested that, although reeler hemispheres had more active neurons, their rate of activation was slightly lower than those found in wild-type mice. Also, the reeler networks appeared to become increasingly decorrelated with age.

\section{Coactive networks in reeler layer 1 are blocked by glutamatergic and GABAergic antagonists}

We finally investigated whether the mechanisms underlying the networks correlations was different in reeler hemispheres. For this purpose, we repeated with reeler (Fig. 9E) the same pharmacological experiments used in wild type (Fig. 6E). As opposed to wild-type hemispheres, in reeler the addition of $50 \mathrm{mM} \mathrm{KCl}$ ACSF produced a significant increase in the total correlations, as measured with our global $p$ value. Like in wild-type mice, the 
A

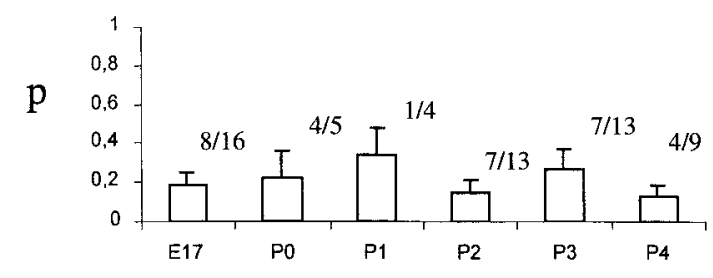

B

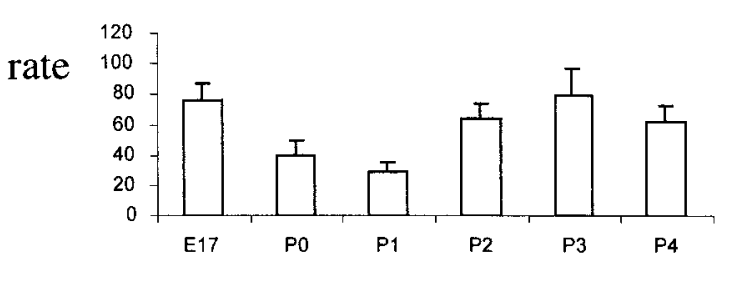

C

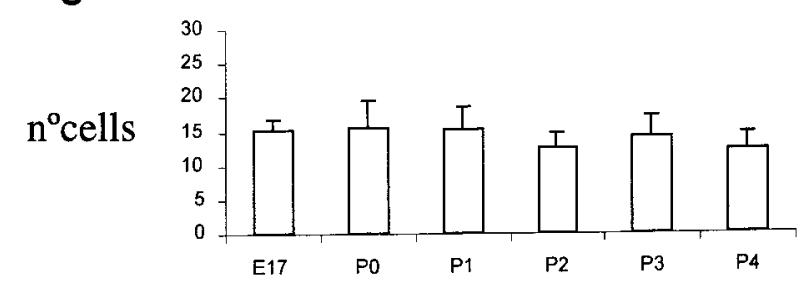

D

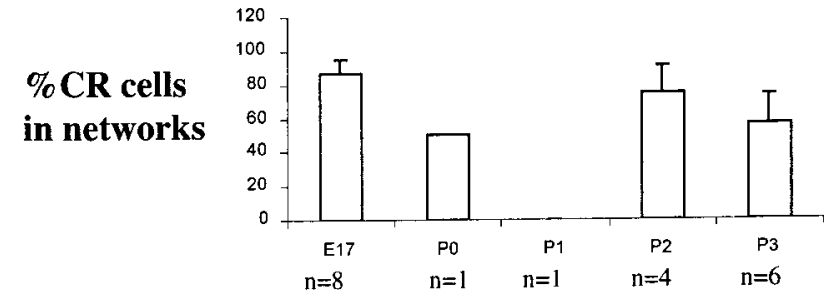

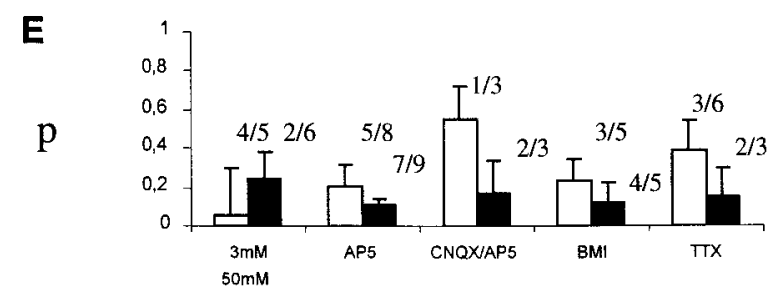

\section{Pharmacology}

Figure 6. Quantification of the spontaneous activity in wild-type hemispheres and pharmacological blockade of the networks. $A$, Histogram of the degree of correlation (as measured by the $p$ statistic; see Materials and Methods) as a function of age. A lower $p$ indicates a high degree of pairwise correlation. The bars represent the mean $p$, and the error bars represent the SE. The fraction represents the number of experiments that had significant $(p<0.05)$ correlations, divided by the total number of experiments. $B$, Histogram of the activation rate (number of transients/cell $/ 10^{4}$ sec) as a function of age. The total number of experiments as in $A$. $C$, Histogram of the number of active cells as a function of age. $D$, Histogram of the percentage of the active CR cells that form part of a network, divided by the total number of CR cells. For each age, the number of experiments in which active CR were identified is given below the histogram. E, Pharmacological effects on the networks. Histogram of the average $p$ value (as above) under 3 and 50 $\mathrm{mm} \mathrm{K}^{+}$ACSF, AP-5 $(50 \mu \mathrm{M})$, AP-5-CNQX $(50-20 \mu \mathrm{M})$, BMI $(30 \mu \mathrm{M})$, and TTX $(1 \mu \mathrm{M})$. White bars are the mean $p$ value under each test, and black bars represent control experiments using $50 \mathrm{~mm} \mathrm{~K}{ }^{+}$ACSF. The fraction represents the number of experiments that had significant $(p<0.05)$ correlations, divided by the total number of experiments. Note how AP-5, CNQX-AP-5, BMI, and TTX increase the average $p$ value (i.e., decorrelate the networks).

sodium channel blocker TTX, the glutamate blocker APV, and the GABA-A receptor blocker BMI produced a significant increase in the correlations, indicating that these networks were also synaptically mediated and that glutamatergic and GABAergic pathways were also involved.

\section{DISCUSSION}

\section{Synaptic control of spontaneous correlated calcium transients}

For this study, our rationale was to use calcium imaging from populations of neurons to detect their activity patterns and then apply correlation analysis to the spatiotemporal activity patterns to identify which neurons had correlated activity which were statistically significance difference from chance. Although cal- cium is a second messenger, the availability of sensitive calcium indicators that can be bulk-loaded using AM esters (Tsien, 1981; Yuste, 1999), and the tight correlation between neuronal activity and increases in intracellular free calcium concentration $\left(\left[\mathrm{Ca}^{2+}\right]_{\mathrm{i}}\right)$ make it possible to use calcium imaging to indirectly monitor neuronal activity from populations of neurons (Yuste and Katz, 1991; O’Donovan et al., 1993; Wong et al., 1993; Smetters et al., 1999).

We focused in characterizing the patterns of spontaneous calcium transients present in layer 1 from hemispheres from wildtype and reeler embryonic and early postnatal mice. The cellular mechanisms that cause these calcium transients are still unclear. Because they are not blocked by TTX, they cannot be directly produced by sodium action potentials. Because of their slow 


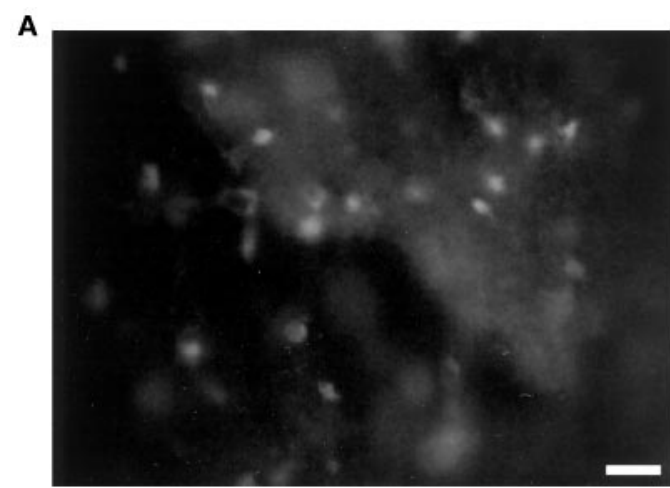

B

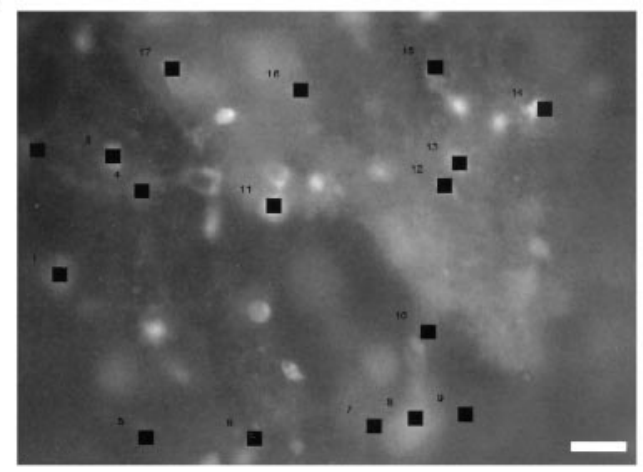

C
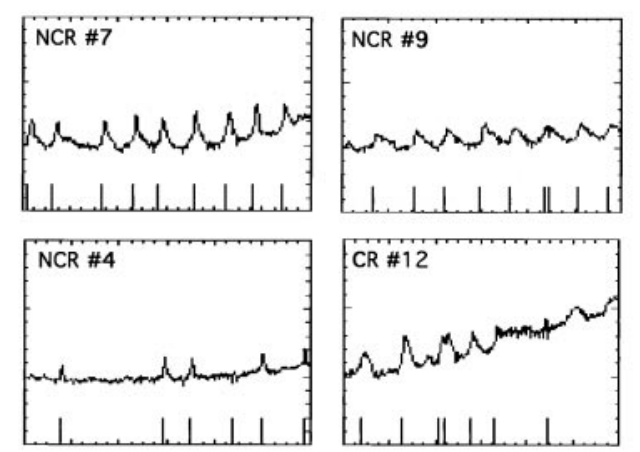

D

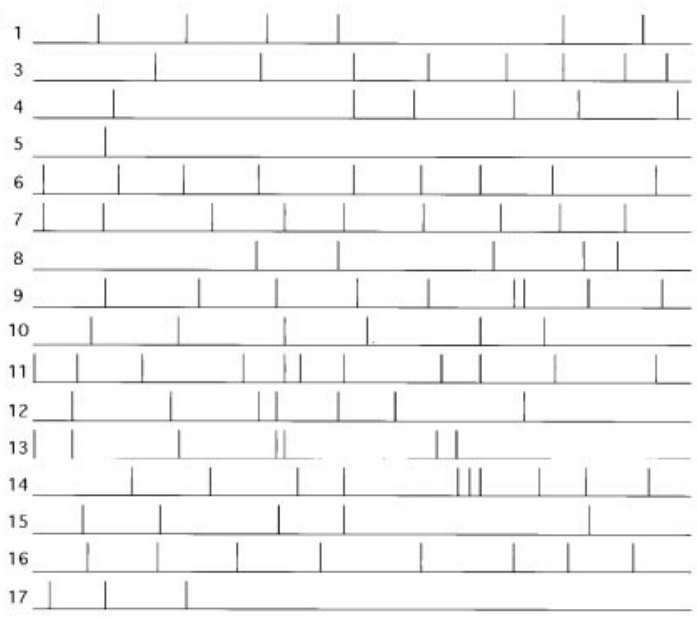

Figure 7. Spontaneous calcium transients in reeler layer 1. A, Fluorescence image of a cortical hemisphere from a P3 reeler mouse loaded with fura-2 AM. Scale bar, $20 \mu \mathrm{m}$. $B$, Cells chosen for the analysis. Cell 12 was identified as a CR. $C$, Plots of $-\Delta F / F$ over time measured in four representative cells during spontaneous activity. Time axis, $\% 1200 \mathrm{sec} ;-\Delta F / F$ axis, $-5 / 10$ (percent). $D$, Composite raster plot of all cells chosen. Note that the spontaneous activity also does not follow any clear pattern, although correlated activation of two or more cells can be detected. Duration, 1200 sec.

kinetics and high amplitudes, these transients are likely caused by the release of calcium from internal stores (Berridge, 1998). In fact, in both cultured pyramidal neurons (Jacobs and Meyer, 1997) and pyramidal neurons in neocortical slices (A. Tashiro and R. Yuste, unpublished observations), release of calcium from internal stores has been demonstrated. Regardless of the cellular mechanism, in this study we use the spontaneous calcium transient as an assay to characterize the activity of the network. Like in our previous study in rat layer 1 (Schwartz et al., 1998), we find that these calcium transients are statistically correlated among groups of neurons and that application of TTX, GABAergic, and glutamatergic blockers block the correlations, without affecting the rate of occurrence of the transients. This pharmacological sensitivity confirms that these correlations are not an artifact of our statistical analysis and indicates that the time of occurrence of a calcium transient is under synaptic control, perhaps mediated by calcium-induced calcium release.

\section{Distributed circuits in layer 1 and possible roles of network activity}

We interpret our results as evidence of specific synaptic networks in developing layer 1. These microcircuits are superimposed in the same territories, and we have encountered many cases in which a particular neuron can be part of different coactivation events. Therefore, our results are in principle consistent with a distributed network (Hopfield, 1982; Douglas and Martin, 1998) present in layer 1 .

What is the role of these coactive networks in developing layer 1? We can imagine two major functions: a developmental one or a computational one. Like in the developing visual system (Shatz, 1990; Katz and Shatz, 1996), coordinated activity in developing layer 1 could be implicated in activity-dependent developmental rules. Coactivation of layer 1 networks could have consequences for the formation of intrinsic connections within layer 1. Also, because of the importance of CR neurons in controlling neuronal migration (Caviness and Sidman, 1973; D'Arcangelo et al., 1995; Hirotsune et al., 1995; Ogawa et al., 1995; Soriano et al., 1997) and pathfinding (Del Río et al., 1997; Borrell et al., 1999) and perhaps even pyramidal neuron development (Marín-Padilla and Marín-Padilla, 1982), network activity of layer 1 could influence the formation of connections in other cortical layers, particularly because migrating neuroblasts and apical dendrites from most pyramidal neurons establish synaptic contacts in layer 1 (MarínPadilla and Marín-Padilla, 1982). Indeed, because of the resilience of orientation maps in neocortex to manipulations of cortical inputs during development, it has been suggested that spatially modulated activity of the marginal zone could generate a protomap of intrinsic cortical connections (Schmidt et al., 1999). In fact, the long-range projections of CR neurons could be related to the clustered horizontal connections (Galuske and Singer, 
A

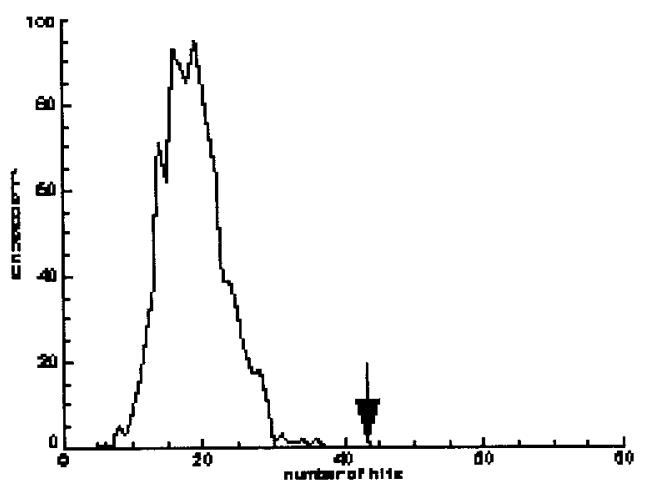

B

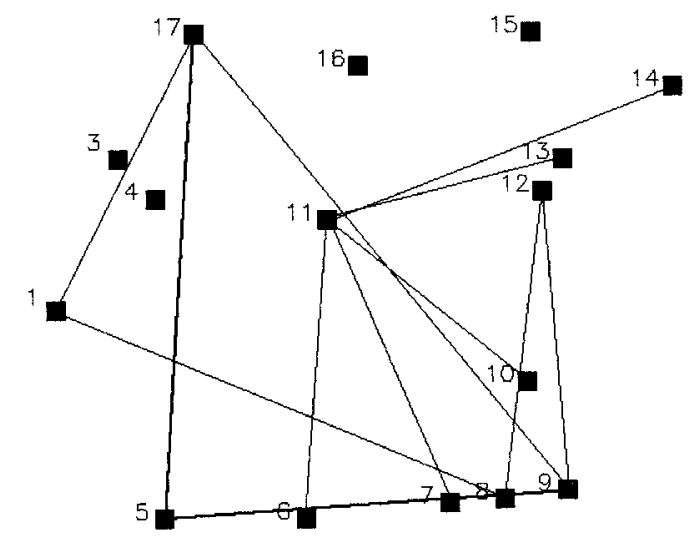

C

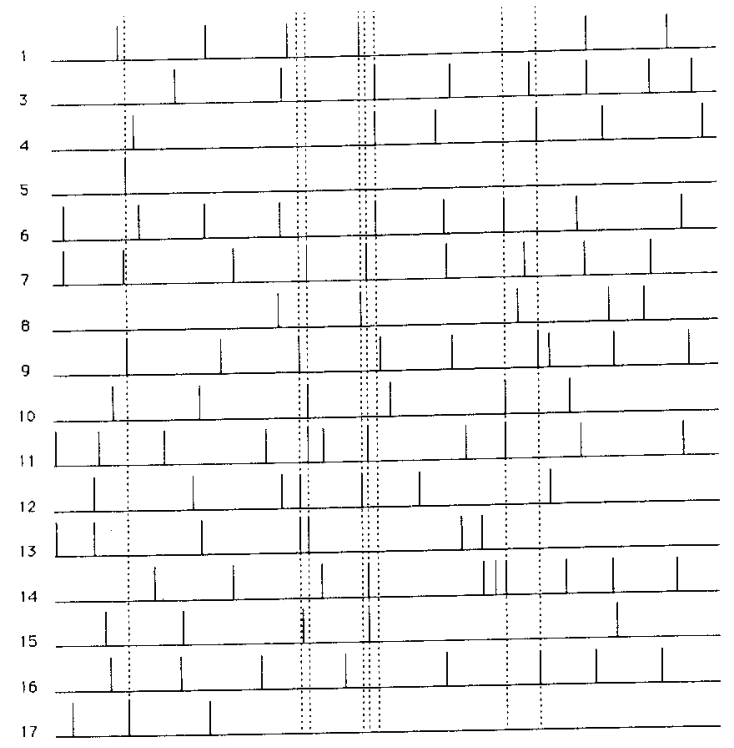

D

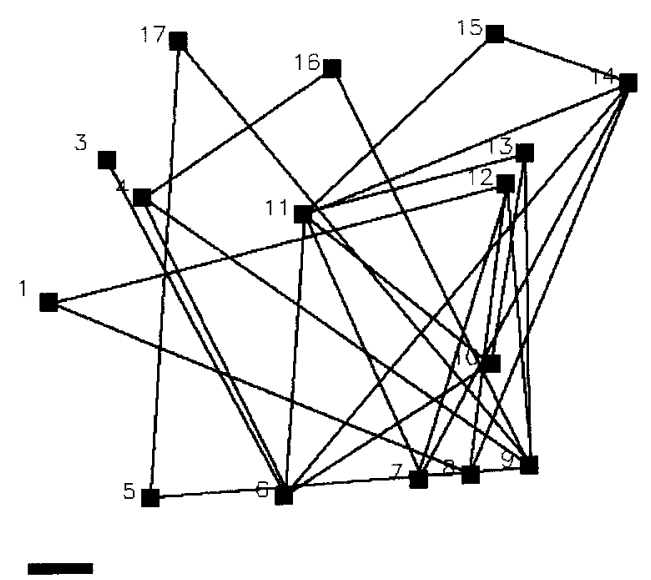

Figure 8. Networks of CR and NCR cells in reeler layer 1. A, Distribution of pairwise correlations found in the real (arrow) and simulated data set from Figure 7. The number of correlated events in the real data set is higher than the tail of the gaussian distribution obtained with 1000 Monte Carlo simulations (see Materials and Methods). B, Correlation map of cells imaged in Figure 7. $C$, Raster plot of an experiment marking groups of cells that fire simultaneously (dotted lines). $D$, Correlation map based on the groups of cells firing simultaneously in $C$. Note how CR cell 12 is correlated with NCR cells. Scale bar, $10 \mu \mathrm{m}$.

1996), which are also present in rodents (Lohmann and Roerig, 1994). Further experiments, either correlating the projections from CR neurons or the networks we describe with orientation maps or clustered horizontal projections, could be used to test this hypothesis.

Another possible role of these coactive networks could relate to the information processing performed by layer 1 , both during the developing and adult circuit. Both anatomical (Rockland and Virga, 1989) and physiological (Cauller and Kulics, 1991) data suggest that layer 1 is a specialized recipient of feedback information coming from higher cortical areas, so these layer 1 networks could be involved in the gating or control of feedback to the cortical circuit.

It seems to us that a direct way to test the putative developmental or functional role of layer 1 networks is the local inf usion of TTX, which decouples the networks. In one study, TTX infusion in the superficial layers of late postnatal kitten cortex blocked ocular dominance plasticity, without any gross disturbance to the cortical architecture (Reiter et al., 1986). A similar type of experiments with local TTX infusion in layer 1 at embryonic or early postnatal ages could be useful to evaluate the importance of layer 1 activity during development.

\section{Role of CR in coordinating layer 1 network activity in wild-type and reeler mice}

We draw three main conclusions from our results: (1) CR neurons participate in the correlated networks in mouse layer 1, (2) these networks exist in embryonic marginal zone, and (3) there are small differences in these networks between wild-type and reeler mice. In our previous study in rat developing layer 1 , CR neurons did not participate in the networks, although this could have been caused by the low activation rates. In the mouse, most CR neurons that are active are part of a correlated network. This indicates that CR neurons, which have prominent axonal and dendritic arborization in layer 1 , synapse and receive synapses, respectively, from particular groups of non-CR neurons, thus forming neuronal microcircuits in developing layer 1. 
A

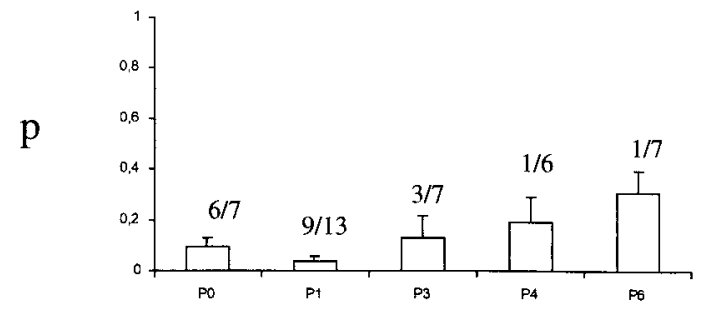

B

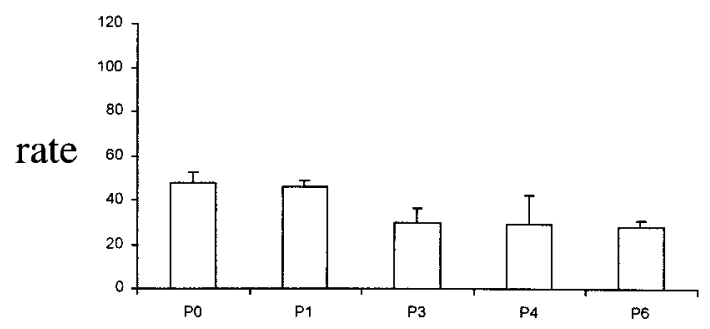

C

$\mathrm{n}^{\mathrm{o}}$ cells

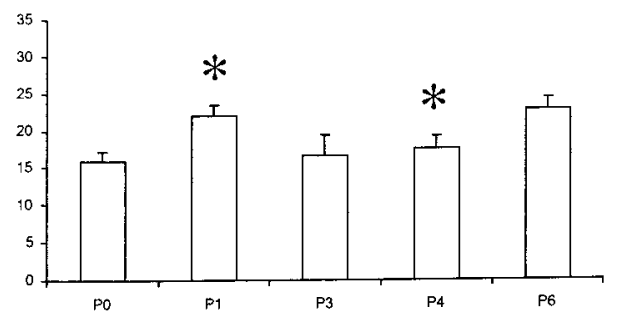

D

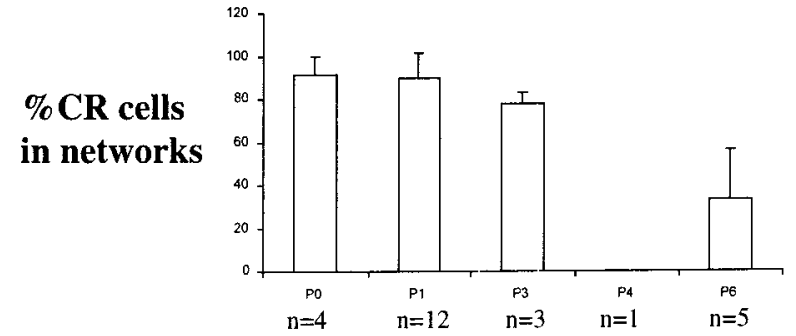

E

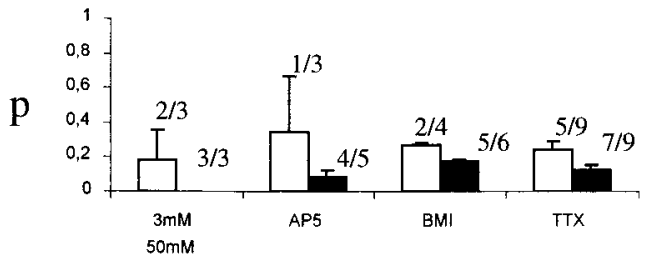

Pharmacology

Figure 9. Quantification of the spontaneous activity in reeler and pharmacological blockade of the networks. Same convention as in Figure 4. A, Histogram of the degree of correlation as a function of age. Note how the networks become more decorrelated with increasing age. $B$, Histogram of the activation rate as a function of age. $C$, Histogram of the number of active cells as a function of age. Asterisks mark ages that are statistically significantly larger $(p>0.05)$ than wild-type hemisphere (see Fig. $6 C)$. D. Percentage of the active CR cells that form part of a network. $E$, Pharmacological effects on the reeler networks. Histogram of the average $p$ value (as above) under $3 \mathrm{~mm} \mathrm{~K}{ }^{+}$ACSF, AP-5 (50 $\left.\mu \mathrm{M}\right)$, BMI (30 $\left.\mu \mathrm{M}\right)$, and TTX (1 $\left.\mu \mathrm{M}\right)$. White bars are the mean $p$ value under each test, and black bars represent control experiments using $50 \mathrm{mM} \mathrm{K}^{+}$ACSF. Note how, in reeler layer 1, AP-5, BMI, and TTX also increase the average $p$ value (i.e., decorrelate the networks).

Also, in our previous work, we never explored embryonic ages. Together with evidence showing synaptic contacts at the subplate (Hermann et al., 1994), our data show that the earliest generated cortical neurons can sustain spontaneous correlated activity. The presence of this spontaneous correlated activity during the earliest phase of cortical development could have a major effect in the fate and connectivity of later generated neurons.

Given the devastating effect of the reeler phenotype in the cortical architecture, we find it surprising that we cannot detect larger differences in layer 1 networks between wild-type and reeler mice. We have confidence that our statistical approach is valid, because it can be affected specifically with pharmacological blockers and also because the multiple correlations tests detect correlations in both wild-type and reeler that are extremely difficult to explain by chance (Figs. 3C, 8C). It remains possible that other assays of the circuit may show more pronounced differences, but at this point our conclusion is that the layer 1 circuits in wild-type and reeler mice are basically similar.
Nevertheless, in our study, small differences were found between wild-type and reeler. The reeler hemispheres appear to have more correlated activity early in their development (Fig. $9 A)$. Also, neurons in reeler hemispheres show a smaller rate of activation, albeit the number of active cells is slightly higher (Fig. $9 B)$. It is possible that the increased thalamic innervation found in reeler layer 1 (Molnar et al., 1998) could help synchronize better these marginal zone networks.

\section{Development of circuits in reeler: implications for pathfinding mechanisms in neocortex}

Why are the layer 1 networks relatively intact in reeler mice? One possibility is that the intrinsic circuitry in layer 1 is normal in reeler mice. Thus, although reelin has major effects in regulating neuronal migration (Caviness and Sidman, 1973) and axonal growth (Del Río et al., 1997), the neurons located in layer 1 themselves would somehow be "immune" to the lack of reelin. Further experiments characterizing in detail the anatomical con- 
nectivity present in reeler layer 1 could address this interesting scenario.

An alternative possibility, which we favor, is that layer 1 is actually disrupted in reeler but that the axonal pathfinding mechanisms responsible for setting up the microcircuitry in layer 1 and between layer 1 and other cortical layers can overcome the disruption of the cortical architecture. This idea is consistent with previous functional studies of reeler cortex. For example, retinotopy, thalamocortical, and cortico-cortical projections and receptive fields of transcallosal neurons in reeler are indistinguishable from that of normal mice (Simmons and Pearlman, 1982, 1983; Simmons et al., 1982). Given the highly specific connectivity that is thought to underlie the building of receptive fields in the cortex, it seems to us that the precise axonal pathfinding mechanisms and/or synaptic rearrangements that occurs in wild-type animals are basically intact in reeler neocortex. This would imply that gradient information is not essential for intracortical axonal pathfinding and the mechanisms responsible for this precise connectivity are so robust that the axons can still find their correct targets despite their abnormal positions.

\section{REFERENCES}

Berridge MJ (1998) Neuronal calcium signaling. Neuron 21:13-26.

Borrell V, Del Río JA, Alcantara S, Derer M, Martinez A, D'Arcangelo G, Nakajima K, Mikoshiba K, Derer P, Curran T, Soriano E (1999) Reelin regulates the development and synaptogenesis of the layerspecific entorhino-hippocampal connections. J Neurosci 19:1345-1358.

Cauller LJ, Kulics AT (1991) The neural basis of the behaviourally relevant N1 component of the somatosensory-evoked potentials of S1 cortex of awake monkeys: evidence that backward cortical projection signals conscius touch sensation. Exp Brain Res 84:607-619.

Caviness VSJ, Sidman RL (1973) Time of origin of corresponding cell classes in the cerebral cortex of normal and mutant reeler mice: an autoradiographic analysis. J Comp Neurol 148:141-151.

D'Arcangelo G, Miao GG, Chen S-C, Soarse HD, Morgan JI, Curran T (1995) A protein related to extracellular matrix proteins deleted in the mouse mutant reeler. Nature 374:719-723.

De Bergeyck V, Nakajima K, Lambert de Rouvroit C, Naerhuyzen B, Goffinet A, Miyata T, Ogawa M, Mikoshiba K (1997) A truncated Reelin protein is produced but not secreted in the "Orleans" reeler mutation (Reln[rl-Orl]). Brain Res Mol Brain Res 50:85-90.

Del Río JA, Martinez A, Fonseca M, Auladell C, Soriano E (1995) Glutamate-like immunoreactivity and fate of Cajal-Retzius cells in the murine cortex as identified with calretinin antibody. Cereb Cortex $1: 13-21$.

Del Río JA, Heimrich B, Borrell V, Förster E, Drakew A, Alcántara S, Nakajima K, Miyata T, Ogawa M, Mikoshiba K, Derer P, Frotscher M, Soriano E (1997) A role for Cajal-Retzius cells and reelin in the development of hippocampal connections. Nature 285:70-74.

Derer P, Derer M (1990) Cajal-Retzius ontogenesis and death in mouse brain visualized with horseradish peroxidase and electron microscopy. Neuroscience 36:839-856.

Douglas RJ, Martin KAC (1998) Neocortex. In: The synaptic organization of the brain. (Shepherd GM, ed), pp 459-511. Oxford: Oxford UP.

Gabbott PL, Somogyi P (1986) Quantitative distribution of GABAimmunoreactive neurons in the visual cortex (area 17) of the cat. Exp Brain Res 61:323-331.

Galuske RA, Singer W (1996) The origin and topography of long-range intrinsic projections in cat visual cortex: a developmental study. Cereb Cortex 6:417-430.

Herrmann K, Antonini A, Shatz CJ (1994) Ultrastructural evidence for synaptic interactions between thalamocortical axons and subplate neurons. Eur J Neurosci 6:1729-1742.

Hestrin S, Armstrong WE (1996) Morphology and physiology of cortical neurons in layer I. J Neurosci 16:5290-5300.
Hirotsune S, Takahara T, Sasaki N, Hirose K, Yoshiki A, Ohashi T, Kusakabe M, Murakami Y, Muramatsu M, Watanabe S, Nakao K, Katsuki M, Hayashizaki Y (1995) The reeler gene encodes a protein with an EGF-like motif expressed by pioneer neurons. Nat Genet $10: 77-83$

Hopfield JJ (1982) Neural networks and physical systems with emergent collective computational abilities. Proc Natl Acad Sci USA 79:2554-2558.

Huntley GW, Jones EG (1990) Cajal-Retzius cells in developing monkey neocortex show immunoreactivity for calcium-binding proteins. J Neurocytol 19:200-212.

Jacobs JM, Meyer T (1997) Control of action potential-induced $\mathrm{Ca}^{2+}$ signaling in the soma of hippocampal neurons by $\mathrm{Ca}^{2+}$ release from intracellular stores. J Neurosci 17:4129-4135.

Katz LC, Shatz CJ (1996) Synaptic activity and the construction of cortical circuits. Science 274:1133-1138.

Lohmann H, Rorig B (1994) Long-range horizontal connections between supragranular pyramidal cells in the extrastriate visual cortex of the rat. J Comp Neurol 344:543-558.

Marín-Padilla M (1972) Prenatal ontogenetic history of the principal neurons of the neocortex of the cat (Felix Domestica.): a Golgi study. II. Developmental differences and their significances. Z Anat Entwicklungsgesch 136:125-142.

Marín-Padilla M (1984) Neurons of layer I. A developmental analysis. In: Cerebral cortex, Vol I, Cellular components of the cerebral cortex (Peters A, Jones EG, ed), pp 1-30. New York: Plenum.

Marín-Padilla M, Marín-Padilla TM (1982) Origin, prenatal development and structural organization of layer 1 of the human cerebral (motor) cortex. A golgi study. Anat Embryol 164:161-206.

Meyer G, Soria JM, Martinez-Galan JR, Martin-Clemente B, Fairen A (1998) Different origins and developmental histories of transient neurons in the marginal zone of the fetal and neonatal rat cortex. J Comp Neurol 10:493-518.

Molnar Z, Adams R, Goffinet AM, Blakemore C (1998) The role of the first postmitotic cortical cells in the development of thalamocortical innervation in the reeler mouse. J Neurosci 18:5746-5765.

O’Donovan MJ, Ho S, Sholomenko G, Yee W (1993) Real-time imaging of neurons retrogradely and anterogradely labelled with calciumsensitive dyes. J Neurosci Methods 46:91-106.

Ogawa M, Miyata T, Nakajima K, Yagyu K, Seike M, Ikenaka K, Yamamoto H, Mikoshiba K (1995) The reeler gene-associated antigen on Cajal-Retzius neurons is a crucial molecule for laminar organization of cortical neurons. Neuron 14:899-912.

Parnavelas JG, Edmunds S (1983) Further evidence that Retzius-Cajal cells transform to nonpyramidal neurons in the developing rat visual cortex. J Neurocytol 12:863-871.

Rakic P (1974) Neurons in rhesus monkey visual cortex: systematic relation between time of origin and eventual disposition. Science 183:425-427.

Ramón y Cajal S (1904) La textura del sistema nerviosa del hombre y los vertebrados. Madrid: Moya.

Reiter HO, Waitzman DM, Stryker MP (1986) Cortical activity blockade prevents ocular dominance plasticity in the kitten visual cortex. Exp Brain Res 65:182-188.

Rockland KS, Virga A (1989) Terminal arbors of individual "feedback" axons projecting from $\mathrm{V} 2$ to $\mathrm{V} 1$ in the macaque monkey: a study using immunocytochemistry of anterogradely transported Phaseolus vulgaris leucoagglutinin. J Comp Neurol 285:54-72.

Schmidt KE, Galuske RAW, Singer W (1999) Matching the modules: cortical maps and long-range instrinsic connections in visual cortex during development. J Neurobiol 41:10-17.

Schwartz T, Rabinowitz D, Unni VK, Kumar VS, Smetters DK, Tsiola A, Yuste R (1998) Networks of coactive neurons in developing layer 1. Neuron 20:1271-1283.

Shatz CJ (1990) Impulse activity and the patterning of connections during CNS development. Neuron 5:745-756.

Simmons PA, Pearlman AL (1982) Retinotopic organization of the striate cortex (area 17) in the reeler mutant mouse. Brain Res 256:124-126.

Simmons PA, Pearlman AL (1983) Receptive-field properties of transcallosal visual cortical neurons in the normal and reeler mouse. J Neurophysiol 50:838-848.

Simmons PA, Lemmon V, Pearlman AL (1982) Afferent and efferent 
connections of the striate and extrastriate visual cortex of the normal and reeler mouse. J Comp Neurol 211:295-308.

Smetters DK, Majewska A, Yuste R (1999) Detecting action potentials in neuronal populations with calcium imaging. Methods 18:215-221.

Soriano E, Alvarado-Mallart RM, Dumesnil N, Del Río JA, Sotelo C (1997) Cajal-Retzius cells regulate the radial glia phenotype in the adult and developing cerebellum and alter granule cell migration. Neuron 18:563-577.

Takahara T, Ohsumi T, Kuromitsu J, Shibata K, Sasaki N, Okazaki Y, Shibata H, Sato S, Yoshiki A, Kusakabe M, Muramatsu M, Ueki M, Okuda K, Hayashizaki Y (1996) Dysfunction of the Orleans reeler gene arising from exon skipping due to transposition of a full-length copy of an active L1 sequence into the skipped exon. Hum Mol Genet 5:989-993.
Tsien RY (1981) A non-disruptive technique for loading calcium buffers and indicators into cells. Nature 290:527-528.

Wong ROL, Meister M, Shatz CJ (1993) Transient period of correlated bursting activity during the development of the mammalian retina. Neuron 11:923-938.

Yuste R (1999) Loading populations neurons in slices with AM calcium indicators. In: Imaging neurons: a laboratory manual, Chap 34 (Yuste R, Lanni, F, Konnerth A, eds), pp 1-9. Cold Spring Harbor, NY: Cold Spring Harbor Laboratory.

Yuste R, Katz LC (1991) Control of postsynaptic $\mathrm{Ca}^{2+}$ influx in developing neocortex by excitatory and inhibitory neurotransmitters. Neuron 6:333-344.

Zhou F-M, Hablitz JJ (1996) Postnatal development of membrane properties of layer I neurons in rat neocortex. J Neurosci 16:1131-1139. 